\title{
Synthesis of Photoactivatable Analogues of Lysophosphatidic Acid and Covalent Labeling of Plasma Proteins
}

\author{
Zaiguo $\mathbf{L i}^{1}$, Daniel L. Baker 2,3 , Gabor Tigyi ${ }^{3,4}$, and Robert Bittman ${ }^{1}{ }^{*}$ \\ 1 Department of Chemistry and Biochemistry, Queens College of the City University of New York, Flushing, \\ New York 11367-1597 \\ 2Department of Medicine and the Vascular Biology and Genomics \& Bioinformatics Centers of Excellence, \\ The University of Tennessee Health Science Center, Memphis, Tennessee 38163
}

3The University of Tennessee Cancer Institute, Memphis, Tennessee 38163

4Department of Physiology, The University of Tennessee Health Science Center, Memphis, Tennessee 38163

\section{Abstract}

Lysophosphatidic acid bearing a benzophenone group in either the $s n-1$ or $s n-2$ chain of an oleoyltype ester or oleyl-type ether chain and ${ }^{32} \mathrm{P}$ in the phosphate group were synthesized. The benzophenone moiety was introduced by selective hydroboration of the double bond of enyne $\mathbf{1 1}$ at low temperature, followed by Suzuki reaction with 4-bromobenzophenone. The key intermediates for the preparation of ester-linked LPA $\mathbf{1}$ and $\mathbf{3}$ were obtained in one pot by a modified DIBAL-H reduction of orthoformate intermediate $\mathbf{2 2}$. These probes were shown to covalently modify a single protein target in rat plasma containing albumin and several protein targets in rat plasma containing a low level of albumin.

\section{Introduction}

Lysophosphatidic acid (LPA) has the simplest structure of natural phospholipids, yet has attracted significant attention because of the diversity and importance of its biological effects.

1-5 LPA is not a single compound; rather, it comprises a family of related mediators that differ in the length and degree of unsaturation of a hydrocarbon chain linked to a glycerol backbone via ester, ${ }^{6}$ ether, ${ }^{7}$ or vinyl ether ${ }^{8}$ bonds at either the $s n-1$ or $s n-2$ position. Different LPA family members have distinct biological activities. ${ }^{9}$ LPA plays a key role in a myriad of physiological processes, including $\mathrm{Ca}^{2+}$ flux, vascular and neuronal function, cell growth/death, and cell migration. $^{2,10}$ It is now appreciated that LPA has numerous intracellular, extracellular, and cell surface targets. LPA exerts its activities mainly through several cell-surface $\mathrm{G}$ proteincoupled receptors (GPCR), including the widely reported $\mathrm{LPA}_{1}, \mathrm{LPA}_{2}$, and $\mathrm{LPA}_{3}$ receptor subtypes. Recently, the $\mathrm{LPA}_{4} / \mathrm{GPR} 23 / \mathrm{P} 2 \mathrm{Y} 9$ receptor $^{11}$ and the nuclear transcription factor PPAR $\gamma 12$ were identified as LPA receptors. LPA also interacts with numerous binding proteins, including albumin ${ }^{13}$ and gelsolin. ${ }^{14}$ It has been speculated that interactions with binding proteins may modulate the biological activity of LPA.

\footnotetext{
*To whom correspondence should be addressed. Phone: (718) 997-3279. Fax: (718) 997-3349. Email: robert.bittman@qc.cuny.edu. Supporting Information Available: Procedures for enzymatic incorporation of $\left[{ }^{32} \mathrm{P}\right]$-phosphate into the benzophenone-containing analogues, for covalent modification of plasma proteins, and for the preparation of compounds 9 and $\mathbf{1 0}$, and ${ }^{1} \mathrm{H}$ and ${ }^{13} \mathrm{C}$ NMR spectra for all new compounds and intermediates. This material is available free of charge via the Internet at http://pubs.acs.org.
} 
Despite recent progress elucidating many of the biological properties of LPA, a detailed understanding of the key roles of LPA in many disease processes has not yet been achieved. To gain insights into the protein targets of LPA, we have prepared photoreactive analogues of LPA. Photoactivatable lipid analogues have been widely employed to study hydrophobic binding sites of lipid targets. ${ }^{15}$ Recently, we reported the first synthesis and characterization of two photoactivable analogues of sphingosine 1-phosphate (S1P). ${ }^{16}$ Likewise, photoactivatable analogues of bioactive glycerophospholipids 17 and lysosphingophospholipids ${ }^{18}$ have been reported recently. One previous study reported the synthesis and characterization of a photoreactive LPA analogue containing a trifluoromethylphenyldiazirine group for labeling of fetal bovine serum and LPA responsive cells. ${ }^{19}$ In this paper, we report the syntheses of additional photoactivable analogues of acyland $O$-alkyl-linked LPAs in which the long chain resembles an oleoyl (ester) or oleyl (ether) chain, respectively. The rationale for this approach is that the oleoyl chain has been shown to represent the maximally effective fatty acyl chain of natural LPAs in previous structure-activity studies. ${ }^{20}$ We have prepared both the 2-lyso (1 and $\left.\mathbf{2}\right)$ and 1-lyso ( $\mathbf{3}$ and $\left.\mathbf{4}\right)$ regioisomeric analogues of [ $\left.{ }^{32} \mathrm{P}\right]-\mathrm{LPA}$, as well as $O$-methoxymethyl (MOM)-protected photoreactive analogues of [ $\left.{ }^{32} \mathrm{P}\right]$-LPA (denoted as $\mathbf{2 0 P}$ and $\mathbf{2 7 P}$ ). In the current analogues, benzophenone was employed as the photoprobe for labeling of proteins because it is readily activated with long-wavelength UV light, is stable in most of the chemical reactions used during the synthesis of the probe, and generally yields covalent products modified at a single site. ${ }^{21}$ In the four probes reported herein, the benzophenone moiety is linked to the end of a $\Delta^{9}$ cis hydrocarbon chain. These analogues were characterized via the covalent modification of rat plasma proteins.

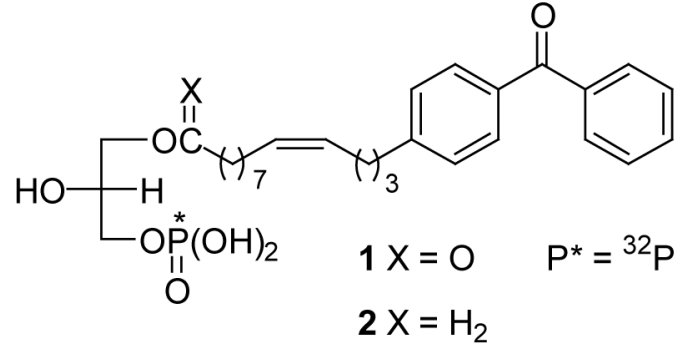

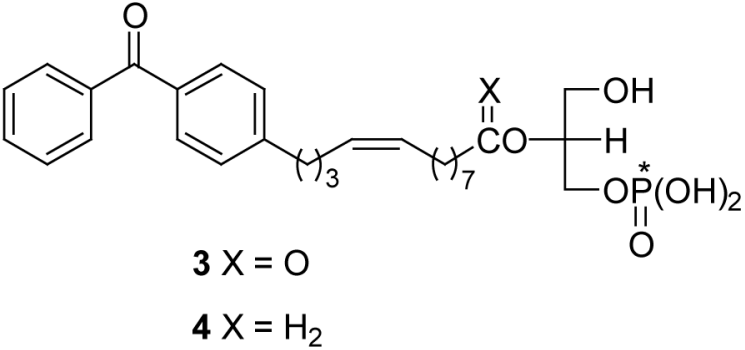

\section{Results and Discussion}

\section{Retrosynthetic Analysis}

Our retrosynthetic strategy for the synthesis of $\mathbf{1}$ and $\mathbf{2}$ is outlined in Scheme 1. Analogues $\mathbf{1}$ and 2 were envisioned as being produced via enzymatic phosphorylation and deprotection of 2-MOM-protected 3-hydroxy-glyceryl ester $5(X=O)$ or ether $\left(X=\mathrm{H}_{2}\right)$, respectively.

Compound 5 can be generated by the selective removal of the $s n-3$ protecting group (PG) from 6, whereas intermediate $\mathbf{6}$ is accessible from carboxylic acid $7(X=O)$ or from the corresponding alcohol $\left(\mathrm{X}=\mathrm{H}_{2}\right)$. The introduction of the benzophenone probe into 7 may be achieved by the regioselective addition of 9 -BBN to the double bond in $\mathbf{8}$, provided that no reaction occurs at the internal triple bond, followed by Suzuki coupling with 4bromobenzophenone. Compounds $\mathbf{3}$ and $\mathbf{4}$ can be prepared from the regioisomers of 5-8 using similar schemes.

\section{Conversion of 2-Decyn-1-ol to Alcohol 14}

Scheme 2 outlines the synthesis of $\Delta^{9}$-alcohol 14 . The acetylene zipper reaction of commercially available 2-decyn-1-ol ${ }^{22}$ gave terminal acetylide $\mathbf{9}$. After the hydroxy group was protected as a THP ether to give $\mathbf{1 0}$ in nearly quantitative yield, addition of allyl bromide to the lithium anion of $\mathbf{9}$ provided enyne $\mathbf{1 1}$ in $\mathbf{7 9 \%}$ yield. The benzophenone moiety was introduced by selective hydroboration of the double bond of $\mathbf{1 1}$ at low temperature, without 
reaction of the organoborane with the triple bond, followed by Suzuki reaction of the terminal boronate with 4-bromobenzophenone. After the THP group of $\mathbf{1 2}$ was removed, Lindlarcatalyzed hydrogenation of the triple bond in $\mathbf{1 3}$ afforded $Z$ alcohol 14 in very high yield.

\section{Synthesis of Ester-linked LPA Probes 1 and 3. Conversion of Alcohol 14 to Glyceride 20}

Oxidation of alcohol 14 with PDC gave acid 15, which was converted to ester 16 by reaction with $(R)$-isopropylidene glycerol (Scheme 3). After removal of the acetonide protecting group in $\mathbf{1 6}$ afforded diol 17, monoacylation of the resultant primary hydroxy group was accomplished according to a reported procedure ${ }^{23}$ with 1 equiv. of FMOC-chloroformate, providing secondary alcohol $\mathbf{1 8}$ in $28 \%$ yield based on diol $\mathbf{1 7}$. This yield is comparable to that reported with a similar diol. ${ }^{23}$ Treatment of 18 with $\mathrm{MOMCl}$ provided glyceride $\mathbf{1 9}$, and removal of the FMOC group (10\% piperidine in $\mathrm{CH}_{2} \mathrm{Cl}_{2}$ ) afforded 20. Although this multistep synthesis is straightforward, the overall yield of ester $\mathbf{2 0}$ is low and the method does not allow for the preparation of the regioisomer of $\mathbf{2 0}$. To overcome these deficiencies, an alternative synthetic strategy was designed (see Scheme 4).

\section{Syntheses of 1 and 3 via 3-O-PMP-sn-glycerol (21)}

Our revised synthetic scheme begins with the conversion of 3-O-PMP-sn-glycerol (21) 24 to glyceride 20 and its regioisomer 27 (Scheme 4). The MOM protecting group was introduced into diol 21 prior to ester formation by transesterification with trimethyl orthoformate using a modification of a previously reported procedure. ${ }^{25}$ The key step in this scheme is the protection of one of the hydroxy groups of diol $\mathbf{2 1}$ as a MOM ether via orthoformate intermediate $\mathbf{2 2}$, followed by reduction with DIBAL-H in toluene. When the reduction was conducted at $-78^{\circ}$ C, regioisomers $\mathbf{2 3}$ and $\mathbf{2 4}$ were obtained in a ratio of $23: 1$ and an overall yield of $96 \%$ after chromatography. Thus, this methodology is a highly efficient route to the precursor of 1-lysoLPA product 3 , but not to the 2-lyso-LPA product $\mathbf{1}$. We altered the reduction conditions to obtain an adequate amount of primary alcohol $\mathbf{2 4}$ for conversion to 1-acyl-LPA product $\mathbf{1}$, which is needed in the photolabeling experiments. When the DIBAL-H reduction was carried out at $0{ }^{\circ} \mathrm{C}$, compound 24 was obtained in $14 \%$ yield, which sufficed for the preparation of 1. Esterification of $\mathbf{2 3}$ and $\mathbf{2 4}$ with acid $\mathbf{1 5}$ using Mitsunobu reaction conditions, followed by removal of the PMP group in $\mathbf{2 5}$ and $\mathbf{2 6}$ with CAN, provided $\mathbf{2 7}$ and 20. Compounds $\mathbf{1}$ and $\mathbf{3}$ were obtained by phosphorylation of $\mathbf{2 7}$ and $\mathbf{2 0}$ with diacylglycerol kinase (DGK) and [ ${ }^{32} \mathrm{P}$ ] ATP. ${ }^{26}$ The final step, deprotection of the MOM group of $\mathbf{2 0 P}$ and $27 \mathbf{P}$, was accomplished in quantitative yield with trimethylsilyl bromide in dry $\mathrm{CH}_{2} \mathrm{Cl}_{2}$ at $0{ }^{\circ} \mathrm{C}$.

\section{Synthesis of Ether-linked LPA Probes 2 and 4}

Scheme 5 depicts the strategy we used to introduce an $O$-alkyl chain bearing a benzophenone probe into the $s n-1$ or $s n-2$ positions of glycerol. Reaction of diol 21 with dibutyltin oxide afforded cyclic tin intermediate 29, 27 which was used without purification. Ethers $\mathbf{3 0}$ and $\mathbf{3 1}$ were obtained in $80 \%$ and $10 \%$ yields, respectively, by nucleophilic substitution of bromide $\mathbf{2 8}$ with intermediate $\mathbf{2 9}$. After the hydroxy group in $\mathbf{3 0}$ or $\mathbf{3 1}$ was protected as a MOM ether, the PMP group was removed with CAN to give precursor $\mathbf{3 4}$ or $\mathbf{3 5}$ in high yield. Ether-linked probes $\mathbf{2}$ and $\mathbf{4}$ were obtained from $\mathbf{3 4}$ and $\mathbf{3 5}$ using the same phosphorylation and deprotection methodology described for the preparation of $\mathbf{1}$ and $\mathbf{3}$.

\section{Plasma Protein Photolabeling}

The goal of this research was to generate tools that can be used to distinguish targets of individual LPA family members, i.e., acyl vs. $O$-alkyl and $s n-1$ vs. $s n-2$ linked aliphatic benzophenones. To that end, we tested five of the synthesized target compounds and intermediates for the ability to photolabel plasma proteins. Probes $\mathbf{1}$ and $\mathbf{2}$ allow for a comparison of the $s n-1$ acyl- vs. $O$-alkyl analogues whereas $\mathbf{2}$ and $\mathbf{4}$ allow for a comparison of 
the $s n-1$ vs. $s n-2$ regioisomers. Comparisons between compounds $\mathbf{1}$ and $\mathbf{3}$ were not made because of facile acyl migration inherent in probe $3{ }^{28}$ However, the $s n-3$ phosphorylation products (20P and 27P) of synthetic intermediates 20 and 27 afford additional comparison between the acyl regioisomers of LPA without the risk of acyl migration. Plasma from the Sprague-Dawley rat ("normal rat plasma," NRP) contains $19.4 \mathrm{mg}$ of albumin per mL, ${ }^{29}$ and was used as a surrogate for normal human plasma. Conversely, plasma from the Nagase analbuminemic rat ("analbuminemic rat plasma," ARP) contains only $0.4 \mathrm{mg}$ of albumin per $\mathrm{mL}{ }^{29}$ This material was used as a tool to examine binding to plasma proteins other than albumin.

Benzophenone-containing LPA probes were characterized by UV-dependent labeling of plasma proteins (Figure 1). Probes 1, 2, 4, 20P, or 27P all showed time-(Figure 1A) and concentration- (data not shown) dependent labeling of predominantly one protein band in NRP. Based on the fact that LPA was initially purified from serum as biological activity associated with albumin 13 and the size of the labeled band in this study $(\sim 70 \mathrm{kDa})$, we conclude that this protein is likely albumin. In contrast, 4 or 5 targets were identified on photolabeling of plasma with a low content of albumin (ARP) with the same probes (Figure 1B). Once again, labeling for all probes was time (Figure 1B) and dose (data not shown) dependent. The intensity of the individual labeled bands varied among the probes but all of the probes modify similar targets in both NRP and ARP. This was expected since these targets are presumed to be transport proteins in which the interactions are based more on hydrophobicity than on stereochemistry or regiochemistry. Further identification and characterization of plasma protein targets of LPAcontaining benzophenones, as well as examination of the pharmacology of these reagents at individual LPA GPCR and cellular targets, is currently underway in our laboratories.

\section{Experimental Section}

\section{Tetrahydro-2-(tridec-12-en-9-ynyloxy)-2H-pyran (11)}

To a solution of alkyne $\mathbf{1 0}(2.00 \mathrm{~g}, 8.40 \mathrm{mmol})$ in $20 \mathrm{~mL}$ of dry THF, $n$-BuLi $(3.5 \mathrm{~mL}, 10.1$ mmol, a $2.89 \mathrm{M}$ solution in hexane) was added at $-78^{\circ} \mathrm{C}$ under $\mathrm{N}_{2}$. After being stirred for 1 $\mathrm{h}$ at $-78^{\circ} \mathrm{C}$, the reaction mixture was warmed to room temperature and stirred for an additional $1.5 \mathrm{~h}$. The mixture was then slowly added to a solution of allyl bromide $(1.22 \mathrm{~g}, 10.1 \mathrm{mmol})$ and $\mathrm{CuI}(100 \mathrm{mg}, 0.50 \mathrm{mmol})$ in $20 \mathrm{~mL}$ of $\mathrm{THF}$ at $-78^{\circ} \mathrm{C}$. After the reaction mixture was stirred overnight at room temperature, the mixture was filtered through a short silica gel column. The solvent was removed, and the residue was purified by chromatography (hexane/ EtOAc 20:1) to afford $11(1.85 \mathrm{~g}, 79 \%)$ as a colorless oil. ${ }^{1} \mathrm{H}$ NMR $\delta 1.24-1.90(\mathrm{~m}, 18 \mathrm{H}), 2.14$ $-2.22(\mathrm{~m}, 2 \mathrm{H}), 2.90-2.97(\mathrm{~m}, 2 \mathrm{H}), 3.34-3.41(\mathrm{~m}, 1 \mathrm{H}), 3.48-3.52(\mathrm{~m}, 1 \mathrm{H}), 3.69-3.76(\mathrm{~m}, 1 \mathrm{H})$, 3.84-3.89 (m, 1H), 4.55-4.59 (m, 1H), 5.06-5.11 (m, 1H), 5.27-5.36 (m, 1H), 5.77-5.84 (m, $1 \mathrm{H}) ;{ }^{13} \mathrm{C}$ NMR $\delta 18.7,19.6,23.1,25.4,26.1,28.8,29.0,29.0,29.3,29.7,30.7,62.2,67.6,76.4$, 82.8, 98.8, 115.5, 133.3; HR-MS $\left[\mathrm{MNa}^{+}\right] \mathrm{m} / z$ calcd $\mathrm{C}_{18} \mathrm{H}_{30} \mathrm{O}_{2} \mathrm{Na} 301.2138$, found 301.2107.

\section{4-(13-(Tetrahydro-2H-pyran-2-yloxy)tridec-4-ynyl)-benzophenone (12)}

A flask charged with $11(1.11 \mathrm{~g}, 4.00 \mathrm{mmol})$ and $15 \mathrm{~mL}$ of THF was cooled to $-15^{\circ} \mathrm{C}$ in a salt-ice bath, and 9-BBN (12 mL, $6.0 \mathrm{mmol}$, a $0.5 \mathrm{M}$ solution in THF) was added dropwise under $\mathrm{N}_{2}$. After the addition, the reaction mixture was warmed to room temperature and stirred for 5 h. 4-Bromobenzophenone (1.04 g, $4.00 \mathrm{mmol}), \mathrm{Pd}\left(\mathrm{PPh}_{3}\right)_{4}(230 \mathrm{mg}, 0.20 \mathrm{mmol})$, DMF $(15 \mathrm{~mL})$, and anhydrous $\mathrm{K}_{3} \mathrm{PO}_{4}(1.57 \mathrm{~g}, 8.00 \mathrm{mmol})$ were added, and the resulting mixture was heated at reflux for $2 \mathrm{~h}$. The reaction mixture was poured into $100 \mathrm{~mL}$ of water and extracted with $\mathrm{CH}_{2} \mathrm{Cl}_{2}(4 \times 40 \mathrm{~mL})$. The combined organic layers were washed with $100 \mathrm{~mL}$ of water and dried $\left(\mathrm{Na}_{2} \mathrm{SO}_{4}\right)$. The solvent was removed under vacuum and the residue was purified by chromatography (hexane/EtOAc 8:1) to provide $12(1.21 \mathrm{~g}, 66 \%$ ) as a colorless oil. ${ }^{1} \mathrm{H}$ NMR $\delta 1.28-1.90(\mathrm{~m}, 20 \mathrm{H}), 2.12-2.22(\mathrm{~m}, 4 \mathrm{H}), 2.80(\mathrm{t}, 2 \mathrm{H}, J=7.6 \mathrm{~Hz}), 3.32-3.40$ 
(m, 1H), 3.43-3.50 (m, 1H), 3.68-3.74 (m, 1H), 3.82-3.87 (m, 1H), 4.53-4.58 (m, 1H), 7.28 $-7.80(\mathrm{~m}, 9 \mathrm{H}) .{ }^{13} \mathrm{C}$ NMR $\delta 18.0,18.5,19.5,25.3,26.0,28.6,28.9,29.2,29.5,30.2,30.6,34.6$, 62.1, 67.4, 77.2, 79.1, 80.9, 98.6, 128.0, 128.3, 129.7, 130.1, 132.0, 135.1, 137.7, 146.9, 196.1; HR-MS $\left[\mathrm{MNa}^{+}\right] \mathrm{m} / z$ calcd for $\mathrm{C}_{31} \mathrm{H}_{40} \mathrm{O}_{3} \mathrm{Na} 483.2870$, found 483.2880 .

\section{4-(13-Hydroxytridec-4-ynyl)-benzophenone (13)}

A solution of $\mathbf{1 2}$ (370 mg, $0.80 \mathrm{mmol}$ ) and a catalytic amount of PPTS in MeOH was heated at reflux for $3 \mathrm{~h}$. Concentration, followed by purification of the residue by chromatography (hexane/EtOAc 4:1), provided 13 (282 mg, 93\%). ${ }^{1} \mathrm{H}$ NMR $\delta 1.25-1.60(\mathrm{~m}, 12 \mathrm{H}), 1.80-1.85$ $(\mathrm{m}, 2 \mathrm{H}), 2.14-2.21(\mathrm{~m}, 4 \mathrm{H}), 2.75(\mathrm{~s}, 1 \mathrm{H}), 2.80(\mathrm{t}, 2 \mathrm{H}, J=7.6 \mathrm{~Hz}), 3.58(\mathrm{t}, 2 \mathrm{H}, J=6.8 \mathrm{~Hz})$, 7.27-7.79 (m, 9H); ${ }^{13} \mathrm{C}$ NMR $\delta 17.9,18.5,25.5,28.5,28.8,28.9,29.1,30.0,32.4,34.5,62.3$, $79.1,80.9,127.9,128.2,129.6,130.1,132.0,134.9,137.5,146.9,196.2 ;$ HR-MS $\left[\mathrm{MNa}^{+}\right] \mathrm{m} /$ $z$ calcd for $\mathrm{C}_{26} \mathrm{H}_{32} \mathrm{O}_{2} \mathrm{Na}$ 399.2294, found 399.2285.

\section{4-((Z)-13-Hydroxytridec-4-enyl)-benzophenone (14)}

Lindlar catalyst (15 mg, 5.5\% by weight) was added to a solution of $\mathbf{1 3}(270 \mathrm{mg}, 0.72 \mathrm{mmol})$ in $10 \mathrm{~mL}$ of $\mathrm{MeOH}$. The mixture was stirred under a hydrogen balloon until the starting alkyne was consumed (monitored by TLC, hexane/EtOAc 2:1). The solvent was removed under vacuum, and the residue was purified by chromatography (hexane/EtOAc 4:1) to give $\mathbf{1 4}$ (262 $\mathrm{mg}, 97 \%)$ as an oil. ${ }^{1} \mathrm{H}$ NMR $\delta 1.25-1.48(\mathrm{~m}, 10 \mathrm{H}) .1 .50-1.56(\mathrm{~m}, 2 \mathrm{H}), 1.68-1.74(\mathrm{~m}, 2 \mathrm{H})$, $1.96-2.13(\mathrm{~m}, 4 \mathrm{H}), 2.45(\mathrm{~s}, 1 \mathrm{H}), 2.69$ (t, $2 \mathrm{H}, J=7.6 \mathrm{~Hz}), 3.59$ (t, $2 \mathrm{H}, J=6.8 \mathrm{~Hz}), 5.33-5.40$ (m, 2H), 7.25-7.77 (m, 9H); ${ }^{13} \mathrm{C}$ NMR $\delta 25.6,26.5,27.1,29.0,29.2,29.3,29.5,30.9,32.5$, 35.2, 62.5, 128.0, 128.2, 128.7, 129.7, 130.1, 130.5, 132.0, 134.9, 137.6, 147.7, 196.4; HRMS $\left[\mathrm{MNa}^{+}\right] \mathrm{m} / z$ calcd for $\mathrm{C}_{26} \mathrm{H}_{34} \mathrm{O}_{2} \mathrm{Na}$ 401.2451, found 401.2454.

\section{(Z)-13-(4-Benzoylphenyl)-9-tridecenoic acid (15)}

A solution of 14 (730 mg, $1.93 \mathrm{mmol})$ and PDC (7.3 g, $19.3 \mathrm{mmol})$ in DMF $(20 \mathrm{~mL})$ was stirred at room temperature for 2 days. Water $(100 \mathrm{~mL})$ was added, and the mixture was extracted with $\mathrm{CH}_{2} \mathrm{Cl}_{2}(3 \times 50 \mathrm{~mL})$. The combined organic layers were washed with water $(100 \mathrm{~mL})$ and dried $\left(\mathrm{Na}_{2} \mathrm{SO}_{4}\right)$. The solvent was removed under vacuum and the residue was purified by chromatography (hexane/EtOAc 2:1) to give $\mathbf{1 5}(657 \mathrm{mg}, 87 \%)$ as a viscous oil. ${ }^{1} \mathrm{H}$ NMR $\delta$ $1.24-1.40(\mathrm{~m}, 8 \mathrm{H}), 1.58-1.75(\mathrm{~m}, 4 \mathrm{H}), 1.96-2.12(\mathrm{~m}, 4 \mathrm{H}), 2.33(\mathrm{t}, 2 \mathrm{H}, J=7.2 \mathrm{~Hz}), 2.70(\mathrm{t}$, $2 \mathrm{H}, J=7.6 \mathrm{~Hz}), 5.33-5.44(\mathrm{~m}, 2 \mathrm{H}), 7.26-7.79(\mathrm{~m}, 9 \mathrm{H}) ;{ }^{13} \mathrm{C}$ NMR $\delta 24.6,26.7,27.2,28.9$, 29.0, 29.1, 29.5, 31.0, 34.0, 35.4, 128.1, 128.3, 128.9, 129.9, 130.3, 130.6, 132.1, 135.0, 137.8, 147.8, 179.9, 196.5; HR-MS $\left[\mathrm{MNa}^{+}\right] \mathrm{m} / z$ calcd for $\mathrm{C}_{26} \mathrm{H}_{32} \mathrm{O}_{3} \mathrm{Na}$ 415.2244, found 415.2255.

\section{1-O-(13-(4-Benzoylphenyl)-9(Z)-tridecenoyl)-3-O-FMOC-sn-glycerol (18)}

DCC $(6.3 \mathrm{mg}, 0.031 \mathrm{mmol})$ and DMAP $(1.0 \mathrm{mg}, 8.1 \mu \mathrm{mol})$ were added to a solution of $\mathbf{1 5}$ (10.0 mg, $0.025 \mathrm{mmol})$ and $(R)$-(-)-2,2-dimethyl-1,3-dioxolane-4-methanol (4.0 mg, 0.031 mmol) in $1 \mathrm{~mL}$ of $\mathrm{CH}_{2} \mathrm{Cl}_{2}$. After the mixture was stirred at room temperature for $40 \mathrm{~h}$, the solvent was removed under vacuum, and the residue was purified by chromatography (hexane/ EtOAc 4:1) to provide (Z)-13-benzoylphenyl-9-tridecenoic acid (S)-(2,2-dimethyl-1,3dioxolan-4-yl)methyl ester (16) (11.9 mg, 92\%). ${ }^{1} \mathrm{H}$ NMR $\delta 1.23-1.37$ (m, 8H), 1.37 (s, 3H), $1.43(\mathrm{~s}, 3 \mathrm{H}), 1.60-1.75(\mathrm{~m}, 4 \mathrm{H}), 1.96-2.12(\mathrm{~m}, 4 \mathrm{H}), 2.34(\mathrm{t}, 2 \mathrm{H}, J=7.6 \mathrm{~Hz}), 2.70(\mathrm{t}, 2 \mathrm{H}, J=$ $7.6 \mathrm{~Hz}), 3.71-3.75(\mathrm{~m}, 1 \mathrm{H}), 4.05-4.18(\mathrm{~m}, 3 \mathrm{H}), 4.28-4.33(\mathrm{~m}, 1 \mathrm{H}), 5.33-5.42(\mathrm{~m}, 2 \mathrm{H}), 7.26$ -7.80 (m, 9H); ${ }^{13} \mathrm{C}$ NMR $\delta 24.8,25.3,26.6,26.7,27.1,29.0,19.0,29.0,29.5,31.0,34.0,35.4$, $64.4,66.2,73.5,109.7,128.1,128.4,128.9,129.8,130.2,130.5,132.1,135.0,137.8,147.7$, 173.5, 196.3 .

One drop of concentrated $\mathrm{HCl}$ was added to a solution of $\mathbf{1 6}(90 \mathrm{mg}, 0.18 \mathrm{mmol})$ in $90 \%$ dioxane $(3 \mathrm{~mL})$. After the mixture was stirred at room temperature for $4 \mathrm{~h}$, the solvent was removed 
under vacuum and the residue was purified by chromatography (hexane/EtOAc 1:1) to give 1((Z)-13-(4-benzoylphenyl)-9-tridecenoyl))-sn-glycerol (17) (60 mg, 73\%). ${ }^{1} \mathrm{H}$ NMR $\delta 1.23$ $-1.38(\mathrm{~m}, 8 \mathrm{H}), 1.55-1.68(\mathrm{~m}, 4 \mathrm{H}), 1.95-2.12(\mathrm{~m}, 4 \mathrm{H}), 2.33(\mathrm{t}, 2 \mathrm{H}, J=7.6 \mathrm{~Hz}), 2.70(\mathrm{t}, 2 \mathrm{H}$, $J=7.6 \mathrm{~Hz}), 2.75(\mathrm{br} \mathrm{s}, 2 \mathrm{H}), 3.55-3.68(\mathrm{~m}, 2 \mathrm{H}), 3.88-3.94(\mathrm{~m}, 1 \mathrm{H}), 4.15(\mathrm{t}, 2 \mathrm{H}, J=4.8 \mathrm{~Hz})$, 5.34-5.43 (m, 2H), 7.25-7.79 (m, 9H); ${ }^{13} \mathrm{C}$ NMR $\delta 24.8,26.6,27.1,29.0,29.0,29.0,29.5$, $31.0,34.0,35.4,63.3,65.0,70.1,128.2,128.3,128.9,129.9,130.3,130.6,132.2,135.0,137.8$, $147.9,174.2,196.7$.

A solution of 17 (58 $\mathrm{mg}, 0.12 \mathrm{mmol})$ and DMAP $(15 \mathrm{mg}, 0.12 \mathrm{mmol})$ in $1 \mathrm{~mL}$ of dry $\mathrm{CH}_{2} \mathrm{Cl}_{2}$ was cooled to $-10^{\circ} \mathrm{C}$ in a salt-ice bath. A solution of FMOC-chloroformate $(32 \mathrm{mg}$, $0.12 \mathrm{mmol}$ ) in $2 \mathrm{~mL}$ of dry $\mathrm{CH}_{2} \mathrm{Cl}_{2}$ was added dropwise. After the reaction mixture was stirred for $30 \mathrm{~min}$, the solution was washed with water $(5 \mathrm{~mL})$ and dried $\left(\mathrm{Na}_{2} \mathrm{SO}_{4}\right)$. A small amount (12 mg) of starting material 17 was recovered after chromatography, and $\mathbf{1 8}(19 \mathrm{mg}, 28 \%)$ was also obtained after chromatography (hexane/EtOAc 1:3). ${ }^{1} \mathrm{H}$ NMR $\delta 1.22-1.76(\mathrm{~m}, 12 \mathrm{H}), 1.95$ $-2.21(\mathrm{~m}, 5 \mathrm{H}), 2.35(\mathrm{t}, 2 \mathrm{H}), J=7.6 \mathrm{~Hz}), 2.70(\mathrm{t}, 2 \mathrm{H}, J=7.6 \mathrm{~Hz}), 4.10-4.28(\mathrm{~m}, 5 \mathrm{H}), 4.41(\mathrm{~d}$, $2 \mathrm{H}, J=7.2 \mathrm{~Hz}), 5.33-5.42(\mathrm{~m}, 2 \mathrm{H}), 7.24-7.80(\mathrm{~m}, 17 \mathrm{H}) ;{ }^{13} \mathrm{C}$ NMR $\delta 24.8,26.7,27.2,29.1$, $29.1,29.6,30.9,31.1,34.1,35.5,46.7,64.8,68.1,68.5,70.1,120.1,125.1,127.2,127.9,128.2$, 129.0, 129.9, 130.3, 130.6, 132.2, 135.1, 137.9, 141.3, 143.2, 147.8, 155.2, 173.8, 196.6, 207.0; HR-MS $\left[\mathrm{MNa}^{+}\right] \mathrm{m} / z$ calcd for $\mathrm{C}_{44} \mathrm{H}_{48} \mathrm{O}_{7} \mathrm{Na} 711.3292$, found 711.3302 .

\section{1-O-(13-(4-Benzoylphenyl)-9(Z)-tridecenoyl)-2-O-methoxymethyl-3-O-FMOC-sn-glycerol (19)}

Chloromethyl methyl ether ( $7 \mathrm{mg}, 87 \mu \mathrm{mol})$ was added to a stirred solution of $\mathbf{1 8}(6 \mathrm{mg}, 8.7$ $\mu \mathrm{mol})$ and $i-\mathrm{Pr}_{2} \mathrm{NEt}(11 \mathrm{mg}, 87 \mu \mathrm{mol})$ in dry $\mathrm{CH}_{2} \mathrm{Cl}_{2}(1 \mathrm{~mL})$ under $\mathrm{N}_{2}$ at $0{ }^{\circ} \mathrm{C}$. After the mixture was stirred at $0{ }^{\circ} \mathrm{C}$ for $2 \mathrm{~h}$ and at room temperature for 2 days, water $(5 \mathrm{~mL})$ and $\mathrm{CH}_{2} \mathrm{Cl}_{2}(5$ $\mathrm{mL}$ ) were added. The organic layer was washed with brine $(5 \mathrm{~mL})$, water $(5 \mathrm{~mL})$, and dried $\left(\mathrm{Na}_{2} \mathrm{SO}_{4}\right)$. Product $19(4.2 \mathrm{mg}, 66 \%$ yield) was obtained after removal of the solvent and purification by chromatography (hexane/EtOAc 4:1). ${ }^{1} \mathrm{H}$ NMR $\delta 1.21-1.39(\mathrm{~m}, 12 \mathrm{H}), 1.57$ $-1.75(\mathrm{~m}, 4 \mathrm{H}), 1.95-2.12(\mathrm{~m}, 4 \mathrm{H}), 2.34(\mathrm{t}, 2 \mathrm{H}, J=7.6 \mathrm{~Hz}), 2.70(\mathrm{t}, 2 \mathrm{H}, J=7.6 \mathrm{~Hz}), 3.40(\mathrm{~s}$, $3 \mathrm{H}), 4.03-4.33(\mathrm{~m}, 5 \mathrm{H}), 4.41(\mathrm{~d}, 2 \mathrm{H}, J=7.1 \mathrm{~Hz}), 4.73(\mathrm{~s}, 2 \mathrm{H}), 5.33-5.44(\mathrm{~m}, 2 \mathrm{H}), 7.24-7.83$ $(\mathrm{m}, 17 \mathrm{H}) ;{ }^{13} \mathrm{C}$ NMR $\delta 24.9,26.8,27.3,29.1,29.6,31.1,34.1,35.5,46.7,55.7,63.0,67.0,70.0$, $72.4,96.0,100.0,120.1,125.1,127.2,127.9,128.2,128.4,129.0,130.0,130.3,130.7,132.2$, 135.1, 137.9, 141.3, 143.3, 147.8, 155.0, 173.4, 196.5; HR-MS $\left[\mathrm{MNa}^{+}\right] \mathrm{m} / z$ calcd for $\mathrm{C}_{46} \mathrm{H}_{52} \mathrm{O}_{8} \mathrm{Na} 755.3560$, found 755.3598 .

\section{1-O-(13-(4-Benzoylphenyl)-9(Z)-tridecenoyl)-2-O-methoxymethyl-sn-glycerol (20) from 19}

Piperidine $(0.2 \mathrm{~mL})$ was added to a solution of $\mathbf{1 9}(1.3 \mathrm{mg}, 1.7 \mu \mathrm{mol})$ in dry $\mathrm{CH}_{2} \mathrm{Cl}_{2}(2 \mathrm{~mL})$ under nitrogen. The mixture was stirred at room temperature until the starting material was consumed (TLC, hexane/EtOAc 4:1). Concentration and purification by chromatography (hexane/EtOAc 2/1) afforded $20(0.6 \mathrm{mg}, 66 \%)$. The $\mathrm{R}_{f}$ and ${ }^{1} \mathrm{H}$ NMR spectrum were identical with data obtained for the same compound prepared from $\mathbf{2 6}$ (see below).

\section{1-(4-Methoxyphenoxy)-3-(methoxymethoxy)propan-(2R)-2-ol (23) and 3-(4- Methoxyphenoxy)-(2R)-2-(methoxymethoxy)propan-1-ol (24)}

Trimethyl orthoformate ( $0.66 \mathrm{~mL}, 6.0 \mathrm{mmol}$ ) was added to a stirred suspension of diol 21 (594 $\mathrm{mg}, 3.0 \mathrm{mmol})$ and $\mathrm{D}-10$-camphorsulfonic acid $(12 \mathrm{mg}, 50 \mu \mathrm{mol})$ in $36 \mathrm{~mL}$ of dry $\mathrm{CH}_{2} \mathrm{Cl}_{2}$ at at room temperature under nitrogen. The reaction mixture was stirred at room temperature until diol 21 was fully consumed (TLC, hexane/EtOAc 1:1). The mixture was cooled to $0{ }^{\circ} \mathrm{C}$, and $12 \mathrm{~mL}$ of DIBAL-H (18 mmol, a $1.5 \mathrm{M}$ solution in toluene) was added slowly. Stirring was continued at $0{ }^{\circ} \mathrm{C}$ until the ortho ester intermediate disappeared (TLC, hexane/EtOAc 4:1). A solution of potassium sodium tartrate $(10.2 \mathrm{~g}, 36.0 \mathrm{mmol})$ in water $(40 \mathrm{~mL})$ was added cautiously to quench the reaction, and the resulting mixture was stirred at room temperature overnight. The organic layer was separated, and the aqueous layer was extracted with 
$\mathrm{CH}_{2} \mathrm{Cl}_{2}(3 \times 30 \mathrm{~mL})$. The combined organic extracts were washed with water $(50 \mathrm{~mL})$ and dried $\left(\mathrm{Na}_{2} \mathrm{SO}_{4}\right.$ and a small amount of $\left.\mathrm{K}_{2} \mathrm{CO}_{3}\right)$. The solvent was removed under vacuum, and the residue was purified by chromatography (a gradient of hexane/EtOAc from 10:1 to 1:1) to provide $603 \mathrm{mg}$ (83\%) of $\mathbf{2 3}$ and $99 \mathrm{mg}$ (14\%) of 24. Data for compound 23: ${ }^{1} \mathrm{H}$ NMR $\delta 3.31$ $(\mathrm{s}, 1 \mathrm{H}), 3.35(\mathrm{~s}, 3 \mathrm{H}), 3.65-3.77(\mathrm{~m}, 5 \mathrm{H}), 3.96(\mathrm{~d}, 2 \mathrm{H}, J=5.8 \mathrm{~Hz}), 4.08-4.15(\mathrm{~m}, 1 \mathrm{H}), 4.65(\mathrm{~s}$, 2H), 6.77-6.86 (m, 4H); ${ }^{13} \mathrm{C}$ NMR $\delta$ 55.0, 55.3, 68.9, 69.2, 69.4, 96.6, 114.4, 115.3, 152.5, 153.8; HR-MS $\left[\mathrm{MNa}^{+}\right] \mathrm{m} / z$ calcd for $\mathrm{C}_{12} \mathrm{H}_{18} \mathrm{O}_{5} \mathrm{Na} 265.1046$, found 265.1049. Data for compound 24: ${ }^{1} \mathrm{H}$ NMR $\delta 2.69(\mathrm{~s}, 1 \mathrm{H}), 3.43(\mathrm{~s}, 3 \mathrm{H}), 3.71-3.86(\mathrm{~m}, 5 \mathrm{H}), 3.93-4.04(\mathrm{~m}, 3 \mathrm{H})$, $4.79(\mathrm{~s}, 2 \mathrm{H}), 6.78-6.87(\mathrm{~m}, 4 \mathrm{H}) ;{ }^{13} \mathrm{C}$ NMR $\delta 55.6,62.9,68.3,78.0,96.7,114.6,115.4,152.6$, 154.0; HR-MS [ $\left.\mathrm{MNa}^{+}\right] \mathrm{m} / z$ calcd for $\mathrm{C}_{26} \mathrm{H}_{34} \mathrm{O}_{2} \mathrm{Na} 265.1046$, found 265.1037 .

\section{1-O-Methoxymethyl-2-O-(13-(4-benzoylphenyl)-9(Z)-tridecenoyl)-3-O-(4-methoxyphenyl)-sn- glycerol (25)}

DIAD (10 mg, $49.5 \mu \mathrm{mol})$ was added to a solution of acid 15 (16 mg, $41.3 \mu \mathrm{mol})$, alcohol 23 $(10 \mathrm{mg}, 41.3 \mu \mathrm{mol})$, and $\mathrm{PPh}_{3}(13 \mathrm{mg}, 49.5 \mu \mathrm{mol})$, in $\operatorname{dry} \operatorname{THF}(2 \mathrm{~mL})$ at $0{ }^{\circ} \mathrm{C}$. After the mixture was warmed to room temperature and stirred for $24 \mathrm{~h}$, water $(5 \mathrm{~mL})$ and $\mathrm{CH}_{2} \mathrm{Cl}_{2}(5 \mathrm{~mL})$ were added. The aqueous layer was extracted with $\mathrm{CH}_{2} \mathrm{Cl}_{2}(3 \times 5 \mathrm{~mL})$, and the combined organic layers were washed twice with water $(5 \mathrm{~mL})$ and dried $\left(\mathrm{Na}_{2} \mathrm{SO}_{4}\right)$. After the solvents were removed under vacuum, the residue was purified by chromatography (hexane/EtOAc $4: 1$ ) to give $25(19 \mathrm{mg}, 76 \%) .{ }^{1} \mathrm{H}$ NMR $\delta 1.24-1.36(\mathrm{~m}, 8 \mathrm{H}), 1.58-1.76(\mathrm{~m}, 4 \mathrm{H}), 1.95-2.12(\mathrm{~m}, 4 \mathrm{H})$, $2.35(\mathrm{t}, 2 \mathrm{H}, J=7.6 \mathrm{~Hz}), 2.70(\mathrm{t}, 2 \mathrm{H}, J=7.6 \mathrm{~Hz}) 3.34(\mathrm{~s}, 3 \mathrm{H}), 3.76(\mathrm{~s}, 3 \mathrm{H}), 3.79(\mathrm{~d}, 2 \mathrm{H}), 4.06$ $-4.13(\mathrm{~m}, 2 \mathrm{H}), 4.64(\mathrm{~s}, 2 \mathrm{H}), 5.29-5.35(\mathrm{~m}, 1 \mathrm{H}), 5.36-5.44(\mathrm{~m}, 2 \mathrm{H}), 6.80-6.87(\mathrm{~m}, 4 \mathrm{H}), 7.27$ -7.82 (m, 9H); ${ }^{13} \mathrm{C}$ NMR $\delta 24.9,26.8,27.3,29.0,29.1,29.2,29.6,31.1,34.3,35.5,55.3,55.7$, $65.8,67.0,70.8,96.5,114.6,115.6,128.2,128.4,129.0,130.0,130.4,130.7,132.2,135.1$, 137.9, 147.8, 152.7, 154.1, 173.3, 196.5; HR-MS $\left[\mathrm{MNa}^{+}\right] \mathrm{m} / z$ calcd for $\mathrm{C}_{38} \mathrm{H}_{48} \mathrm{O}_{7} \mathrm{Na}$ 639.3292, found 639.3298 .

\section{1-O-(13-(4-Benzoylphenyl)-9(Z)-tridecenoyl)-2-O-methoxymethyl-3-O-(4-methoxyphenyl)- sn-glycerol (26)}

Compound 26 was prepared in $78 \%$ yield according to the procedure used to prepare compound 25. ${ }^{1} \mathrm{H}$ NMR $\delta 1.24-1.35(\mathrm{~m}, 8 \mathrm{H}), 1.58-1.78(\mathrm{~m}, 4 \mathrm{H}), 1.95-2.13(\mathrm{~m}, 4 \mathrm{H}), 2.30-2.35(\mathrm{~m}, 2 \mathrm{H})$, $2.68-2.73(\mathrm{~m}, 2 \mathrm{H}), 3.41(\mathrm{~s}, 3 \mathrm{H}), 3.76(\mathrm{~s}, 3 \mathrm{H}), 4.02(\mathrm{~d}, 2 \mathrm{H}, J=5.3 \mathrm{~Hz}), 4.11-4.17(\mathrm{~m}, 1 \mathrm{H})$, 4.22-4.28 (m, 1H), 4.33-4.38 (m, 1H), $4.77(\mathrm{~s}, 2 \mathrm{H}), 5.36-5.42(\mathrm{~m}, 2 \mathrm{H}), 6.80-6.86(\mathrm{~m}, 4 \mathrm{H})$, 7.26-7.82 (m, 9H); ${ }^{13} \mathrm{C}$ NMR $\delta 24.9,26.8,27.2,29.1,29.1,29.2,29.6,31.1,34.1,35.5,55.6$, 55.7, 63.6, 68.2, 73.3, 96.1, 114.6, 115.5, 128.2, 128.3, 129.0, 129.9, 130.3, 130.6, 132.1, 135.1, 137.9, 147.8, 152.7, 154.1, 173.5, 196.5; HR-MS $\left[\mathrm{MNa}^{+}\right] \mathrm{m} / z$ calcd for $\mathrm{C}_{38} \mathrm{H}_{48} \mathrm{O}_{7} \mathrm{Na}$ 639.3292, found 639.3297 .

\section{1-O-Methoxymethyl-2-O-(13-(4-benzoylphenyl)-9(Z)-tridecenoyl)-sn-glycerol (27)}

CAN (181 mg, $0.33 \mathrm{mmol}$ ) was added to a solution of $25(85 \mathrm{mg}, 0.14 \mathrm{mmol})$ in $7 \mathrm{~mL}$ of $\mathrm{CH}_{3} \mathrm{CN} /$ water (6:1) at room temperature. The mixture was stirred until compound $\mathbf{2 5}$ was consumed ( $\sim 1 \mathrm{~h}$, TLC, hexane/EtOAc 1:1), and was then diluted with water $(10 \mathrm{~mL})$ and $\mathrm{CH}_{2} \mathrm{Cl}_{2}(10 \mathrm{~mL})$. The aqueous layer was extracted with $\mathrm{CH}_{2} \mathrm{Cl}_{2}(3 \times 6 \mathrm{~mL})$, and the combined organic extracts were washed with brine $(10 \mathrm{~mL})$, dried $\left(\mathrm{Na}_{2} \mathrm{SO}_{4}\right)$, filtered, and concentrated. The residue was purified by chromatography (hexane/EtOAc 2:1) to furnish 27 (49 mg, $69 \%) .{ }^{1} \mathrm{H}$ NMR $\delta 1.23-1.38(\mathrm{~m}, 8 \mathrm{H}), 1.57-1.77(\mathrm{~m}, 4 \mathrm{H}), 1.96-2.13(\mathrm{~m}, 4 \mathrm{H}), 2.35(\mathrm{t}, 2 \mathrm{H}, J=$ $7.6 \mathrm{~Hz}), 2.70(\mathrm{t}, 2 \mathrm{H}, J=7.6 \mathrm{~Hz}), 3.36(\mathrm{~s}, 3 \mathrm{H}), 3.70-3.83(\mathrm{~m}, 4 \mathrm{H}), 4.63(\mathrm{~s}, 2 \mathrm{H}), 5.01-5.07(\mathrm{~m}$, $1 \mathrm{H}), 5.34-5.45(\mathrm{~m}, 2 \mathrm{H}), 7.27-7.81(\mathrm{~m}, 9 \mathrm{H}) ;{ }^{13} \mathrm{C}$ NMR $\delta 24.9,26.7,27.2,29.1,29.1,29.2$, 29.6, 31.1, 34.3, 35.5, 55.4, 62.3, 66.3, 73.1, 96.6, 128.2, 128.4, 129.0, 130.0, 130.4, 130.6, 132.2, 135.1, 137.9, 147.9, 173.6, 196.6; HR-MS $\left[\mathrm{MNa}^{+}\right] \mathrm{m} / z$ calcd for $\mathrm{C}_{31} \mathrm{H}_{42} \mathrm{O}_{6} \mathrm{Na} 533.2874$, found 533.2865. 


\section{1-O-(13-(4-Benzoylphenyl)-9(Z)-tridecenoyl)-2-O-methoxymethyl-sn-glycerol (20) from Compound 26}

Compound $\mathbf{2 0}$ was prepared in $73 \%$ yield by the same procedure used to prepare compound 27. ${ }^{1} \mathrm{H}$ NMR $\delta 1.24-1.38(\mathrm{~m}, 8 \mathrm{H}), 1.56-1.76(\mathrm{~m}, 4 \mathrm{H}), 1.95-2.17(\mathrm{~m}, 4 \mathrm{H}), 2.33(\mathrm{t}, 2 \mathrm{H}, J=7.6$ $\mathrm{Hz}), 2.71(\mathrm{t}, 2 \mathrm{H}, J=7.6 \mathrm{~Hz}), 3.42(\mathrm{~s}, 3 \mathrm{H}), 3.58-3.71(\mathrm{~m}, 2 \mathrm{H}), 3.80-3.85(\mathrm{~m}, 1 \mathrm{H}), 4.14-4.24$ $(\mathrm{m}, 2 \mathrm{H}), 4.74(\mathrm{~s}, 2 \mathrm{H}), 5.35-5.44(\mathrm{~m}, 2 \mathrm{H}), 7.24-7.82(\mathrm{~m}, 9 \mathrm{H}) ;{ }^{13} \mathrm{C}$ NMR $\delta 24.9,26.7,27.2$, 29.1, 29.1, 29.6, 31.1, 34.1, 35.5, 55.7, 62.6, 63.2, 77.7, 96.6, 128.2, 128.3, 129.0, 129.9, 130.3, 130.6, 132.2, 135.1, 137.9, 147.8, 173.7, 196.5; HR-MS $\left[\mathrm{MNa}^{+}\right] \mathrm{m} / z$ calcd for $\mathrm{C}_{31} \mathrm{H}_{42} \mathrm{O}_{6} \mathrm{Na}$ 533.2874, found 533.2863.

\section{4-((Z)-Bromotridec-4-enyl)-benzophenone (28)}

To $3 \mathrm{~mL}$ of $\mathrm{CH}_{2} \mathrm{Cl}_{2}$ under $\mathrm{N}_{2}$ were added alcohol 14 (108 mg, $\left.0.29 \mathrm{mmol}\right)$ and $\mathrm{Et}_{3} \mathrm{~N}$ (43 mg, $0.43 \mathrm{mmol}$ ) at $0{ }^{\circ} \mathrm{C}$. After the mixture was stirred for $5 \mathrm{~min}$, methanesulfonyl chloride $(49 \mathrm{mg}$, $0.43 \mathrm{mmol}$ ) was added, and the resulting reaction mixture was stirred at room temperature overnight, quenched with $5 \mathrm{~mL}$ of water, and extracted with $\mathrm{CH}_{2} \mathrm{Cl}_{2}(3 \times 5 \mathrm{~mL})$. The combined organic phases were washed with brine, dried $\left(\mathrm{Na}_{2} \mathrm{SO}_{4}\right)$, filtered, and concentrated. The crude mesylate was dissolved in dry THF (5 mL), and lithium bromide $(50 \mathrm{mg}, 0.57 \mathrm{mmol})$ was added. The reaction mixture was heated at reflux overnight, and then cooled to room temperature and poured into water $(5 \mathrm{~mL})$ and $\mathrm{CH}_{2} \mathrm{Cl}_{2}(5 \mathrm{~mL})$. The aqueous phase was extracted with $\mathrm{CH}_{2} \mathrm{Cl}_{2}(3 \times 5 \mathrm{~mL})$. The combined organic phases were washed with water (10 $\mathrm{mL})$, dried $\left(\mathrm{Na}_{2} \mathrm{SO}_{4}\right)$, and concentrated. The resulting yellow oil was purified by chromatography (hexane/EtOAc 10:1) to provide $\mathbf{2 8}(113 \mathrm{mg}, 90 \%)$ as a colorless oil. ${ }^{1} \mathrm{H}$ NMR $\delta 1.22-1.45(\mathrm{~m}, 10 \mathrm{H}), 1.68-1.86(\mathrm{~m}, 4 \mathrm{H}), 1.96-2.12(\mathrm{~m}, 4 \mathrm{H}), 2.70(\mathrm{t}, 2 \mathrm{H}, J=7.8 \mathrm{~Hz}), 3.37$ $(\mathrm{t}, 2 \mathrm{H}, J=6.8 \mathrm{~Hz}), 5.35-5.44(\mathrm{~m}, 2 \mathrm{H}), 7.25-7.82(\mathrm{~m}, 9 \mathrm{H}) ;{ }^{13} \mathrm{C} \mathrm{NMR} \delta 26.6,27.1,28.0,28.6$, 29.1, 29.2, 29.5, 31.0, 32.7, 33.9, 35.4, 128.1, 128.2, 128.9, 129.8, 130.2, 130.5, 132.0, 135.0, 137.8, 147.7, 196.2; HR-MS [MNa $\left.{ }^{+}\right] \mathrm{m} / z$ calcd for $\mathrm{C}_{26} \mathrm{H}_{33} \mathrm{BrONa}$ 463.1607, found 463.1600.

\section{1-O-(13-(4-Benzoylphenyl)-9(Z)-tridecenyl)-3-O-(4-methoxyphenyl)-sn-glycerol (30) and 2-O- (13-(4-Benzoylphenyl)-9(Z)-tridecenyl)-3-O-(4-methoxyphenyl)-sn-glycerol (31)}

Di- $n$-butyltin oxide (64 mg, $0.26 \mathrm{mmol}$ ) was added to a solution of diol 21 (51 $\mathrm{mg}, 0.26 \mathrm{mmol})$ in $3 \mathrm{~mL}$ of $\mathrm{CHCl}_{3} / \mathrm{MeOH}(10: 1)$. After the resulting suspension was heated at reflux for $3 \mathrm{~h}$ to give a clear solution, the solvents were evaporated to give cyclic stannoxane intermediate 29 as a white solid. Cesium fluoride (78 mg, $0.51 \mathrm{mmol})$ and 18-crown-6 (8 mg, $26 \mu \mathrm{mol})$ were added, and the solid mixture was dried overnight under high vacuum. After DMF ( $3 \mathrm{~mL})$ and bromide 28 (71 $\mathrm{mg}, 0.16 \mathrm{mmol}$ ) were added, the reaction mixture was stirred at room temperature for 1 day. Water $(0.5 \mathrm{~mL})$ and EtOAc $(10 \mathrm{~mL})$ were added, and the mixture was stirred for an additional $1 \mathrm{~h}$ and was subsequently filtered through a pad of silica gel to remove an insoluble by-product. The filtrate was washed with water $(5 \mathrm{~mL})$, dried $\left(\mathrm{Na}_{2} \mathrm{SO}_{4}\right)$, and concentrated. The residue was purified by chromatography (hexane/EtOAc 2:1) to provide $30(72 \mathrm{mg}, 80 \%)$ and $31(8.7 \mathrm{mg}, 10 \%)$. Data for compound 30: ${ }^{1} \mathrm{H}$ NMR $\delta 1.21-1.38(\mathrm{~m}, 8 \mathrm{H})$, 1.52-1.76 (m, 4H), 1.94-2.12 (m, 4H), $2.54(\mathrm{br} \mathrm{s}, 1 \mathrm{H}), 2.70(\mathrm{t}, 2 \mathrm{H}, J=7.6 \mathrm{~Hz}), 3.43-3.64(\mathrm{~m}$, $4 \mathrm{H}), 3.75(\mathrm{~s}, 3 \mathrm{H}), 3.93-4.01(\mathrm{~m}, 2 \mathrm{H}), 4.09-4.16(\mathrm{~m}, 1 \mathrm{H}), 5.33-5.45(\mathrm{~m}, 2 \mathrm{H}), 6.79-6.88(\mathrm{~m}$, $4 \mathrm{H}), 7.25-7.82(\mathrm{~m}, 9 \mathrm{H}) ;{ }^{13} \mathrm{C}$ NMR $\delta 26.0,26.7,27.2,29.2,29.4,29.4,29.5,29.6,31.0,35.4$, 55.6, 69.1, 69.7, 71.5, 71.7, 114.6, 115.5, 128.1, 128.3, 128.9, 129.9, 130.3, 130.7, 132.1, 135.1, 137.9, 147.8, 152.7, 154.0, 196.4; HR-MS $\left[\mathrm{MNa}^{+}\right] \mathrm{m} / z$ calcd for $\mathrm{C}_{36} \mathrm{H}_{46} \mathrm{O}_{5} \mathrm{Na} 581.3237$, found 581.3249. Data for compound 31: ${ }^{1} \mathrm{H}$ NMR $\delta 1.22-1.38(\mathrm{~m}, 8 \mathrm{H}), 1.52-1.77(\mathrm{~m}, 4 \mathrm{H}), 1.95$ $-2.14(\mathrm{~m}, 4 \mathrm{H}), 2.68(\mathrm{t}, 2 \mathrm{H}, J=7.8 \mathrm{~Hz}), 3.52-3.86(\mathrm{~m}, 5 \mathrm{H}), 3.76(\mathrm{~s}, 3 \mathrm{H}), 3.94-4.04(\mathrm{~m}, 2 \mathrm{H})$, 5.34-5.45 (m, 2H), 6.79-6.91 (m, 4H), 7.25-7.81 (m, 9H); ${ }^{13} \mathrm{C}$ NMR $\delta 26.1,26.8,27.3,29.3$, 29.5, 29.5, 29.7, 30.1, 31.1, 35.5, 55.7, 62.5, 68.1, 70.7, 78.2, 114.7, 115.5, 128.2, 128.4, 129.0, 130.0, 130.4, 130.8, 132.2, 135.1, 138.0, 147.9, 152.8, 154.0, 196.6; HR-MS $\left[\mathrm{MNa}^{+}\right] \mathrm{m} / z$ calcd for $\mathrm{C}_{36} \mathrm{H}_{46} \mathrm{O}_{5} \mathrm{Na}$ 581.3237, found 581.3252. 
1-O-(13-(4-Benzoylphenyl)-9(Z)-tridecenyl)-2-O-methoxymethyl-3-O-(4-methoxyphenyl)-snglycerol (32)

Chloromethyl methyl ether ( $40 \mathrm{mg}, 497 \mu \mathrm{mol})$ was added under $\mathrm{N}_{2}$ to a stirred solution of $30(56 \mathrm{mg}, 99 \mu \mathrm{mol})$ and $i$ - $\mathrm{Pr}_{2} \mathrm{NEt}(64 \mathrm{mg}, 497 \mu \mathrm{mol})$ in dry $\mathrm{CH}_{2} \mathrm{Cl}_{2}(3 \mathrm{~mL})$ at $0{ }^{\circ} \mathrm{C}$. The reaction mixture was stirred at room temperature for 2 days. The solvent was removed and the residue was purified by chromatography (hexane/EtOAc $4: 1)$ to afford unreacted $\mathbf{3 0}(10 \mathrm{mg})$ and $32(45 \mathrm{mg}, 91 \%) .{ }^{1} \mathrm{H}$ NMR $\delta 1.22-1.38(\mathrm{~m}, 8 \mathrm{H}), 1.52-1.76(\mathrm{~m}, 4 \mathrm{H}), 1.96-2.15(\mathrm{~m}, 4 \mathrm{H})$, $2.70(\mathrm{t}, 2 \mathrm{H}, J=7.8 \mathrm{~Hz}), 3.41(\mathrm{~s}, 3 \mathrm{H}), 3.41-3.50(\mathrm{~m}, 2 \mathrm{H}), 3.56-3.65(\mathrm{~m}, 2 \mathrm{H}), 3.75(\mathrm{~s}, 3 \mathrm{H}), 3.99$ $-4.11(\mathrm{~m}, 3 \mathrm{H}), 4.79(\mathrm{~s}, 3 \mathrm{H}), 5.34-5.45(\mathrm{~m}, 2 \mathrm{H}), 6.79-6.87(\mathrm{~m}, 4 \mathrm{H}), 7.28(\mathrm{~d}, 2 \mathrm{H}, J=8.3 \mathrm{~Hz})$, $7.47(\mathrm{t}, 2 \mathrm{H}, J=7.8 \mathrm{~Hz}), 7.57(\mathrm{t}, 1 \mathrm{H}, J=7.3 \mathrm{~Hz}), 7.72-7.81(\mathrm{~m}, 4 \mathrm{H}) ;{ }^{13} \mathrm{C}$ NMR $\delta$ 26.0, 26.7, $27.2,29.2,29.4,29.4,29.6,29.6,31.1,35.4,55.4,55.6,68.7,70.4,71.7,84.5,96.2,114.5$, 115.4, 128.1, 128.3, 128.9, 129.9, 130.3, 130.7, 132.1, 135.1, 137.9, 147.8, 152.9, 153.8, 196.4; HR-MS $\left[\mathrm{MNa}^{+}\right] \mathrm{m} / z$ calcd for $\mathrm{C}_{38} \mathrm{H}_{50} \mathrm{O}_{6} \mathrm{Na} 625.3500$, found 625.3519 .

\section{1-O-Methoxymethyl-2-O-(13-(4-benzoylphenyl)-9(Z)-tridecenyl)-3-O-(4-methoxyphenyl)-sn- glycerol (33)}

Compound $\mathbf{3 3}$ was prepared in $89 \%$ yield from $\mathbf{3 1}$ by the same procedure used to prepare 32. ${ }^{1} \mathrm{H}$ NMR $\delta 1.22-1.39(\mathrm{~m}, 8 \mathrm{H}), 1.55-1.62(\mathrm{~m}, 2 \mathrm{H}), 1.68-1.76(\mathrm{~m}, 2 \mathrm{H}), 1.97-2.04(\mathrm{~m}, 2 \mathrm{H})$, $2.07-2.13(\mathrm{~m}, 2 \mathrm{H}), 2.70(\mathrm{t}, 2 \mathrm{H}, J=7.8 \mathrm{~Hz}), 3.34(\mathrm{~s}, 3 \mathrm{H}), 3.58-3.80(\mathrm{~m}, 5 \mathrm{H}), 3.76(\mathrm{~s}, 3 \mathrm{H}), 3.97$ $-4.08(\mathrm{~m}, 2 \mathrm{H}), 4.65(\mathrm{~s}, 2 \mathrm{H}), 5.34-5.44(\mathrm{~m}, 2 \mathrm{H}), 6.80-6.88(\mathrm{~m}, 2 \mathrm{H}), 7.26-7.81(\mathrm{~m}, 9 \mathrm{H}) ;{ }^{13} \mathrm{C}$ NMR $\delta 26.0,26.7,27.3,29.3,29.4,29.5,29.7,30.0,31.1,35.5,55.2,55.7,66.9,68.2,70.7$, 77.1, 96.7, 114.6, 115.5, 128.2, 128.3, 128.9, 129.9, 130.3, 130.8, 132.1, 135.1, 137.9, 147.8, 153.0, 153.9, 196.5; HR-MS $\left[\mathrm{MNa}^{+}\right] \mathrm{m} / z$ calcd for $\mathrm{C}_{38} \mathrm{H}_{50} \mathrm{O}_{6} \mathrm{Na} 625.3500$, found 625.3497.

\section{1-O-(13-(4-Benzoylphenyl)-9(Z)-tridecenyl)-2-O-methoxymethyl-sn-glycerol (34)}

Compound 34 was prepared in $86 \%$ yield using the procedure described to prepare compound 27. ${ }^{1} \mathrm{H}$ NMR $\delta 1.24-1.39(\mathrm{~m}, 8 \mathrm{H}), 1.52-1.60(\mathrm{~m}, 2 \mathrm{H}), 1.68-1.77(\mathrm{~m}, 2 \mathrm{H}), 1.97-2.04(\mathrm{~m}, 2 \mathrm{H})$, 2.06-2.13 (m, 2H), $2.70(\mathrm{t}, 2 \mathrm{H}, J=7.6 \mathrm{~Hz}), 3.42(\mathrm{~s}, 3 \mathrm{H}), 3.40-3.80(\mathrm{~m}, 7 \mathrm{H}), 4.75(\mathrm{~s}, 2 \mathrm{H}), 5.34$ $-5.45(\mathrm{~m}, 2 \mathrm{H}), 7.27-7.82(\mathrm{~m}, 9 \mathrm{H}) ;{ }^{13} \mathrm{C}$ NMR $\delta 26.0,26.7,27.3,29.2,29.4,29.4,29.6,29.7$, 31.1, 35.5, 55.6, 63.7, 71.1, 71.8, 78.5, 96.6, 128.2, 128.3, 128.9, 129.9, 130.3, 130.7, 132.1, 135.1, 137.9, 147.8, 196.5; HR-MS $\left[\mathrm{MNa}^{+}\right] \mathrm{m} / z$ calcd for $\mathrm{C}_{31} \mathrm{H}_{44} \mathrm{O}_{5} \mathrm{Na}$ 519.3081, found 519.3079 .

\section{1-O-Methoxymethyl-2-O-(13-(4-benzoylphenyl)-9(Z)-tridecenyl)-sn-glycerol (35)}

The same method used to prepare 34 was used to prepare 35 in $88 \%$ yield. ${ }^{1} \mathrm{H}$ NMR $\delta 1.22$ $-1.40(\mathrm{~m}, 8 \mathrm{H}), 1.52-1.77(\mathrm{~m}, 4 \mathrm{H}), 1.95-2.13(\mathrm{~m}, 4 \mathrm{H}), 2.70(\mathrm{t}, 2 \mathrm{H}, J=7.6 \mathrm{~Hz}), 3.37(\mathrm{~s}, 3 \mathrm{H})$, 3.46-3.77 (m, 7H), $4.63(\mathrm{~s}, 2 \mathrm{H}), 5.34-5.45(\mathrm{~m}, 2 \mathrm{H}), 7.27-7.82(\mathrm{~m}, 9 \mathrm{H}) ;{ }^{13} \mathrm{C}$ NMR $\delta 26.1$, 26.7, 27.3, 29.2, 29.4, 29.5, 29.7, 30.0, 31.1, 35.5, 55.3, 62.6, 67.0, 70.3, 78.5, 96.7, 128.2, $128.3,128.9,129.9,130.3,130.7,132.2,135.1,137.9,147.8,196.5 ; \mathrm{HR}-\mathrm{MS}\left[\mathrm{MNa}^{+}\right] \mathrm{m} / z$ calcd for $\mathrm{C}_{31} \mathrm{H}_{44} \mathrm{O}_{5} \mathrm{Na}$ 519.3081, found 519.3095.

\section{Supplementary Material}

Refer to Web version on PubMed Central for supplementary material.

\section{Acknowledgments}

We thank Dr. George Kaysen, University of California at Davis, for providing analbuminemic rat plasma. Financial support from National Institutes of Health Grant CA92160 is gratefully acknowledged. 


\section{References}

1. Bittman R. Chem. Phys. Lipids 2004;129:111-131. [PubMed: 15081855]

2. Tigyi G, Parrill AL. Prog. Lipid Res 2003;42:498-526. [PubMed: 14559069]

3. Mills GB, Moolenaar WH. Nat. Rev. Cancer 2003;3:582-591. [PubMed: 12894246]

4. Luquain C, Sciorra VA, Morris AJ. Trends Biochem. Sci 2003;28:377-383. [PubMed: 12878005]

5. Ye X, Ishii I, Kingsbury MA, Chun J. Biochim. Biophys. Acta 2002;1585:108-113. [PubMed: 12531543]

6. Baker DL, Desiderio DM, Miller DD, Tolley B, Tigyi G. J. Anal. Biochem 2001;292:287-295.

7. Tokumura A, Sinomiya J, Kishimoto S, Tanaka T, Kogure K, Sugiura T, Satouchi K, Waku K, Fukuzawa K. Biochem. J 2002;365:617-628. [PubMed: 11982483]

8. Liliom K, Fischer DJ, Virag T, Sun G, Miller DD, Tseng JL, Desiderio DM, Seidel MC, Erickson JR, Tigyi G. J. Biol. Chem 1998;273:13461-13468. [PubMed: 9593679]

9. Bandoh K, Aoki J, Taira A, Tsujimoto M, Arai H, Inoue K. FEBS Lett 2000;478:159-165. [PubMed: 10922489]

10. Ishii I, Fukushima N, Ye X, Chun J. Annu. Rev. Biochem 2004;73:321-354. [PubMed: 15189145]

11. Noguchi K, Ishii S, Shimizu T. J. Biol. Chem 2003;278:25600-25606. [PubMed: 12724320]

12. McIntyre TM, Pontsler AV, Silva AR, Hilaire A. St. Xu Y, Hinshaw JC, Zimmerman GA, Hama K, Aoki J, Arai H, Prestwich GD. Proc. Nat. Acad. Sci. USA 2003;100:131-136. [PubMed: 12502787]

13. a Tigyi G, Henschen A, Miledi R. J. Biol. Chem 1991;266:20602-20609. [PubMed: 1939110] b Tigyi G, Miledi R. J. Biol. Chem 1992;267:21360-21367. [PubMed: 1383223]

14. a Meerschaert K, De Corte V, De Ville Y, Vandekerckhove J, Gettemans J. EMBO J 1998;17:59235930. [PubMed: 9774337] b Goetzl EJ, Lee H, Azuma T, Stossel TP, Turck CW, Karliner JS. J. Biol. Chem 2000;275:14573-14578. [PubMed: 10799543]

15. For a recent review, see: Lala AK. Chem. Phys. Lipids 2002;116:177-188. [PubMed: 12093541].

16. Lu X, Cseh S, Byun H-S, Tigyi G, Bittman R. J. Org. Chem 2003;68:7046-7050. [PubMed: 12946147]

17. a Li G, Samadder P, Arthur G, Bittman R. Tetrahedron 2001;57:8925-8932. b Wang P, Blank DH, Spencer TA. J. Org. Chem 2004;69:2693-2702. [PubMed: 15074915]

18. Lu X, Bittman R. J. Org. Chem 2005;70:4746-4750. [PubMed: 15932314]

19. van der Bend RL, Brunner J, Jalink K, van Corven EJ, Moolenaar WH, van Blitterswijk WJ. EMBO J 1992;11:2495-2501. [PubMed: 1321033]

20. Fujiwara Y, Sardar V, Tokumura A, Baker DL, Murakami-Murofushi K, Parrill AL, Tigyi G. J. Biol. Chem 2005;280:35038-35050. [PubMed: 16115890]

21. Dormán G, Prestwich GD. Trends Biotechnol 2000;18:64-77. [PubMed: 10652511]For a review, see 22. Abrams SR, Shaw AC. Org. Synth 8:146-148.Coll.

23. Bibak N, Hajdu J. Tetrahedron Lett 2003;44:5875-5877.

24. a Wang ZM, Zhang XL, Sharpless KB. Tetrahedron Lett 1993;34:2267-2270. b Vilchèze C, Bittman R. J. Lipid Res 1994;35:734-738. [PubMed: 8006527] c Byun H-S, Kumar ER, Bittman R. J. Org. Chem 1994;59:2630-2633. d Marino-Albernas J, Bittman R, Peters A, Mayhew E. J. Med. Chem 1996;39:3241-3247. [PubMed: 8765506]

25. He L, Byun H-S, Bittman R. J. Org. Chem 2000;65:7618-7626. [PubMed: 11076624]

26. Waggoner DW, Gómez-Muñoz A, Dewald J, Brindley DN. J. Biol. Chem 1996;271:16506-16509. [PubMed: 8663293]See Supporting Information for experimental details

27. Yokoyama K, Baker DL, Virag T, Liliom K, Byun H-S, Tigyi G, Bittman R. Biochim. Biophys. Acta 2002;1582:295-308. [PubMed: 12069841]

28. For the occurrence of intramolecular acyl migration in a related lysophospholipid, see a Plückthun A, Dennis EA. Biochemistry 1982;21:1743-1750. [PubMed: 7082643] b Croset M, Brossard N, Polette A, Lagarde M. Biochem. J 2000;345:61-67. [PubMed: 10600639]

29. Hama K, Bandoh K, Kakehi Y, Aoki J, Arai H. FEBS Lett 2002;523:187-192. [PubMed: 12123830]

J Org Chem. Author manuscript; available in PMC 2008 September 11. 
1 or 2

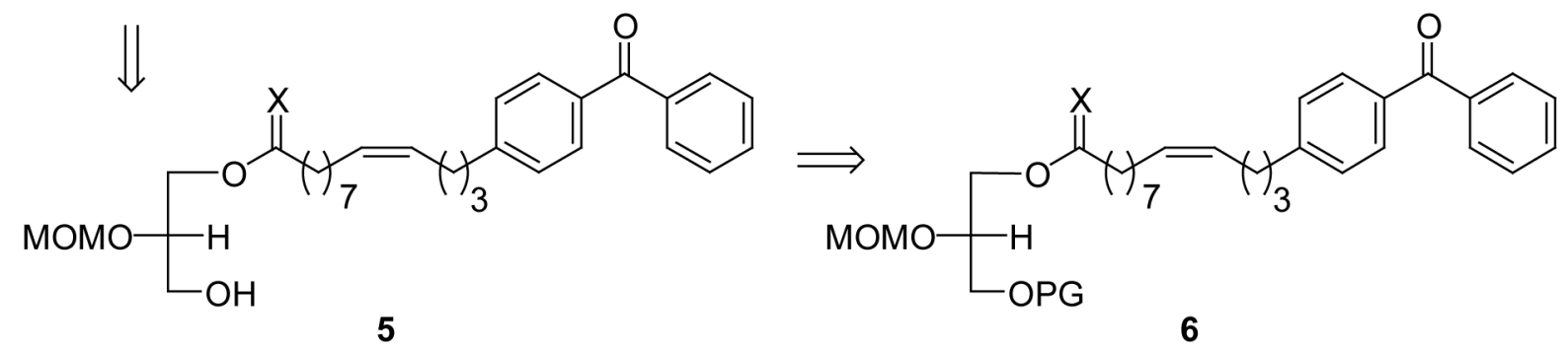<smiles>[X]C(O)=[W]=C(C)c1ccc(C(=O)c2ccccc2)cc1</smiles><smiles>C=CCC#CCC(=O)O</smiles>

Scheme 1.

Retrosynthetic Strategy 


$$
\begin{aligned}
\mathrm{CH}_{3}\left(\mathrm{CH}_{2}\right)_{6} \mathrm{C} \equiv \mathrm{CCH}_{2} \mathrm{OH} \stackrel{\mathrm{a}}{\longrightarrow} \mathrm{HC} \equiv \mathrm{C}\left(\mathrm{CH}_{2}\right)_{8} \mathrm{OR} \\
\text { b } \stackrel{9 \mathrm{R}=\mathrm{H}(90 \%)}{\longrightarrow} 10 \mathrm{R}=\operatorname{THP}(99 \%)
\end{aligned}
$$

$\stackrel{\mathrm{C}}{\longrightarrow} \mathrm{CH}_{2}=\mathrm{CHCH}_{2} \mathrm{C} \equiv \mathrm{C}\left(\mathrm{CH}_{2}\right)_{8} \mathrm{OTHP}$

$11(79 \%)$<smiles></smiles>

$12 \mathrm{R}=\mathrm{THP}(66 \%)$

e

$13 \mathrm{R}=\mathrm{H}(93 \%)$<smiles>O=C(c1ccccc1)c1ccc(NC=CCO)cc1</smiles>

$14(97 \%)$

Scheme 2. Synthesis of Long-Chain Alcohol 14

(a) $\mathrm{LiNH}\left(\mathrm{CH}_{2}\right)_{3} \mathrm{NH}_{2}, t$-BuOK/H${ }_{2} \mathrm{~N}\left(\mathrm{CH}_{2}\right)_{3} \mathrm{NH}_{2}$; (b) DHP, PPTS, $\mathrm{CH}_{2} \mathrm{Cl}_{2}$; (c) i. $n$-BuLi, THF, $-78{ }^{\circ} \mathrm{C}$ to rt; ii. allyl bromide, CuI, THF, $-78^{\circ} \mathrm{C}$; (d) i. 9-BBN, THF, $-15{ }^{\circ} \mathrm{C}$ to rt; ii. $4-$ bromobenzophenone, $\mathrm{Pd}\left(\mathrm{PPh}_{3}\right)_{4}, \mathrm{~K}_{3} \mathrm{PO}_{4}$, THF/DMF, reflux, $2 \mathrm{~h}$; (e) PPTS (cat.), $\mathrm{MeOH}$; (f) $\mathrm{H}_{2}$, Lindlar, $\mathrm{MeOH}$. 


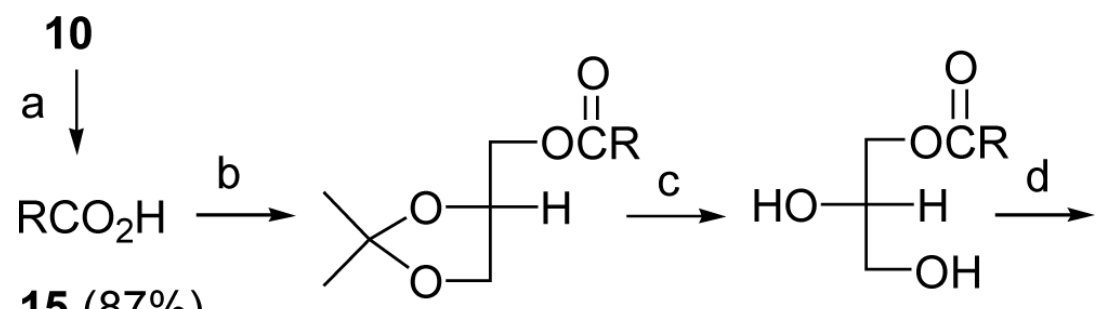
$15(87 \%)$

$16(92 \%)$

$17(73 \%)$<smiles>[R]OCC([R20])COC(=O)CC1c2ccccc2-c2ccccc21</smiles><smiles>[R]OCC(CO)OC([R])=O</smiles>

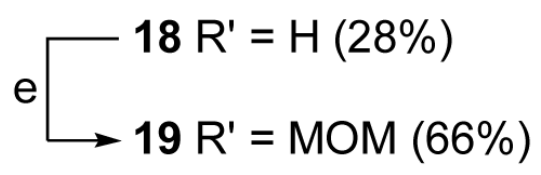<smiles>[R]=[W]/C=C\C(C)CC</smiles>

Scheme 3. Synthesis of Glyceride 20 via FMOC-ester 18 (a) PDC/DMF, rt , 2 d; (b) (R)-(-)-2,2-dimethyl-1,3-dioxolane-4-methanol, DCC, DMAP, $\mathrm{CH}_{2} \mathrm{Cl}_{2}, \mathrm{rt}$; (c) $0.4 \mathrm{~N} \mathrm{HCl} / 90 \%$ dioxane, rt; (d) FMOC-chloroformate, DMAP, $\mathrm{CH}_{2} \mathrm{Cl}_{2},-10$ 。 $\mathrm{C}$; (e) $\mathrm{MOMCl}, i$ - $\mathrm{Pr}_{2} \mathrm{NEt}, \mathrm{CH}_{2} \mathrm{Cl}_{2}$; (f) piperidine, $\mathrm{CH}_{2} \mathrm{Cl}_{2}$. 


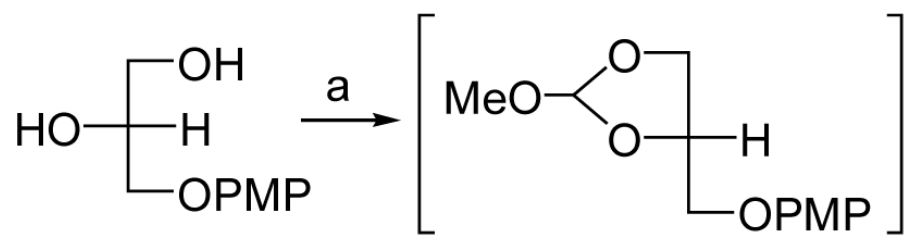

21

22

$a$

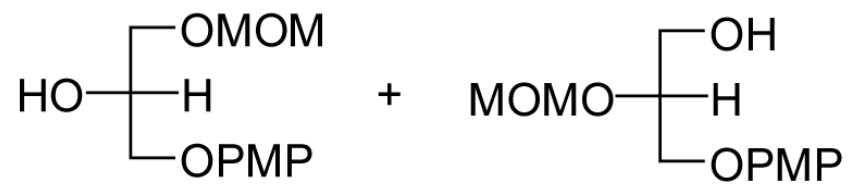

$23(83 \%)$

$24(14 \%)$

$\mathrm{b} \downarrow$

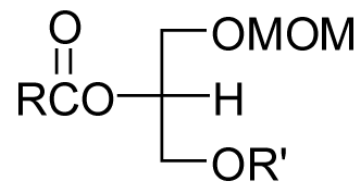

b

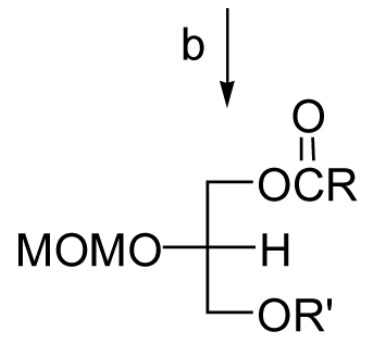

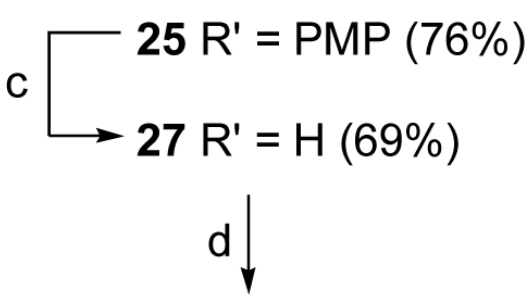

3

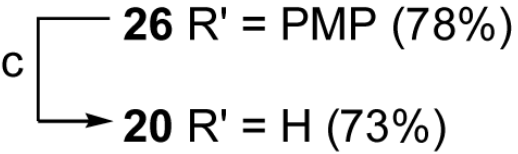

$d \downarrow$

$R$ is the same as in Scheme 2

Scheme 4. Synthesis of 1 and 3

(a) (i). $\mathrm{HC}(\mathrm{OMe})_{3}, \mathrm{CSA}$ (cat.), $\mathrm{CH}_{2} \mathrm{Cl}_{2}$, rt; ii. DIBAL-H, $0{ }^{\circ} \mathrm{C}$; (b) 15, $\mathrm{PPh}_{3}$, DIAD, THF, $0^{\circ}$ C-rt; (c) CAN, $\mathrm{CH}_{3} \mathrm{CN} / \mathrm{H}_{2} \mathrm{O}$ (6:1); (d) i. DGK, $\left[{ }^{32} \mathrm{P}\right] \mathrm{ATP}, \mathrm{pH} 6.6,37^{\circ} \mathrm{C}, 2$ h; ii. TMSBr, $\mathrm{CH}_{2} \mathrm{Cl}_{2}, 0{ }^{\circ} \mathrm{C}$. 
<smiles>Cc1ccc(C(=O)c2ccc(N=CC=CBr)cc2)cc1</smiles>

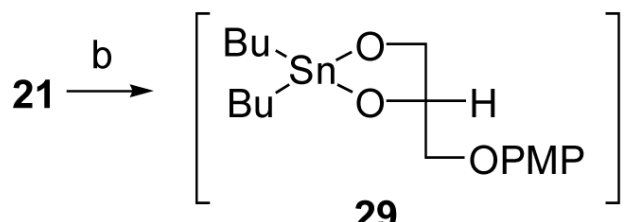

29

b)<smiles>[R]OCC(O)CO[Y7]</smiles><smiles>[R]OCC([R])CO</smiles>

$$
30(80 \%)
$$

$c \downarrow$<smiles>[R]OCC(CO[R])OC</smiles>

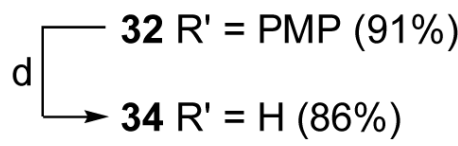<smiles>[TeH][TeH]</smiles>

2
$31(10 \%)$

c<smiles>[R]OCC([R])COC</smiles>

e

4

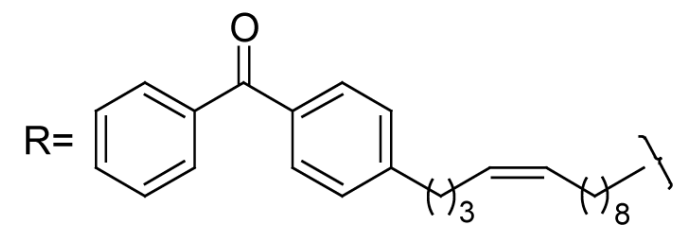

Scheme 5. Synthesis of Ether-linked Probes 2 and 4

(a) (i) $\mathrm{CH}_{3} \mathrm{SO}_{2} \mathrm{Cl}, \mathrm{Et}_{3} \mathrm{~N}, 0^{\circ} \mathrm{C}-\mathrm{rt}$; (ii) $\mathrm{LiBr}$, THF, reflux; (b) (i) $(n-\mathrm{Bu})_{2} \mathrm{SnO}, \mathrm{CHCl}_{3} / \mathrm{MeOH}$ (10:1), reflux; (ii) 28, CsF, 18-crown-6, DMF, rt, 1 d; (c) $\mathrm{MOMCl}, i$ - $\mathrm{Pr}_{2} \mathrm{NEt}, \mathrm{CH}_{2} \mathrm{Cl}_{2}$; (d) CAN, $\mathrm{CH}_{3} \mathrm{CN} / \mathrm{H}_{2} \mathrm{O}$ (6:1); (e) (i) DGK, [ $\left.{ }^{32} \mathrm{P}\right] \mathrm{ATP}$; (ii) $\mathrm{TMSBr}, \mathrm{CH}_{2} \mathrm{Cl}_{2}, 0{ }^{\circ} \mathrm{C}$. 

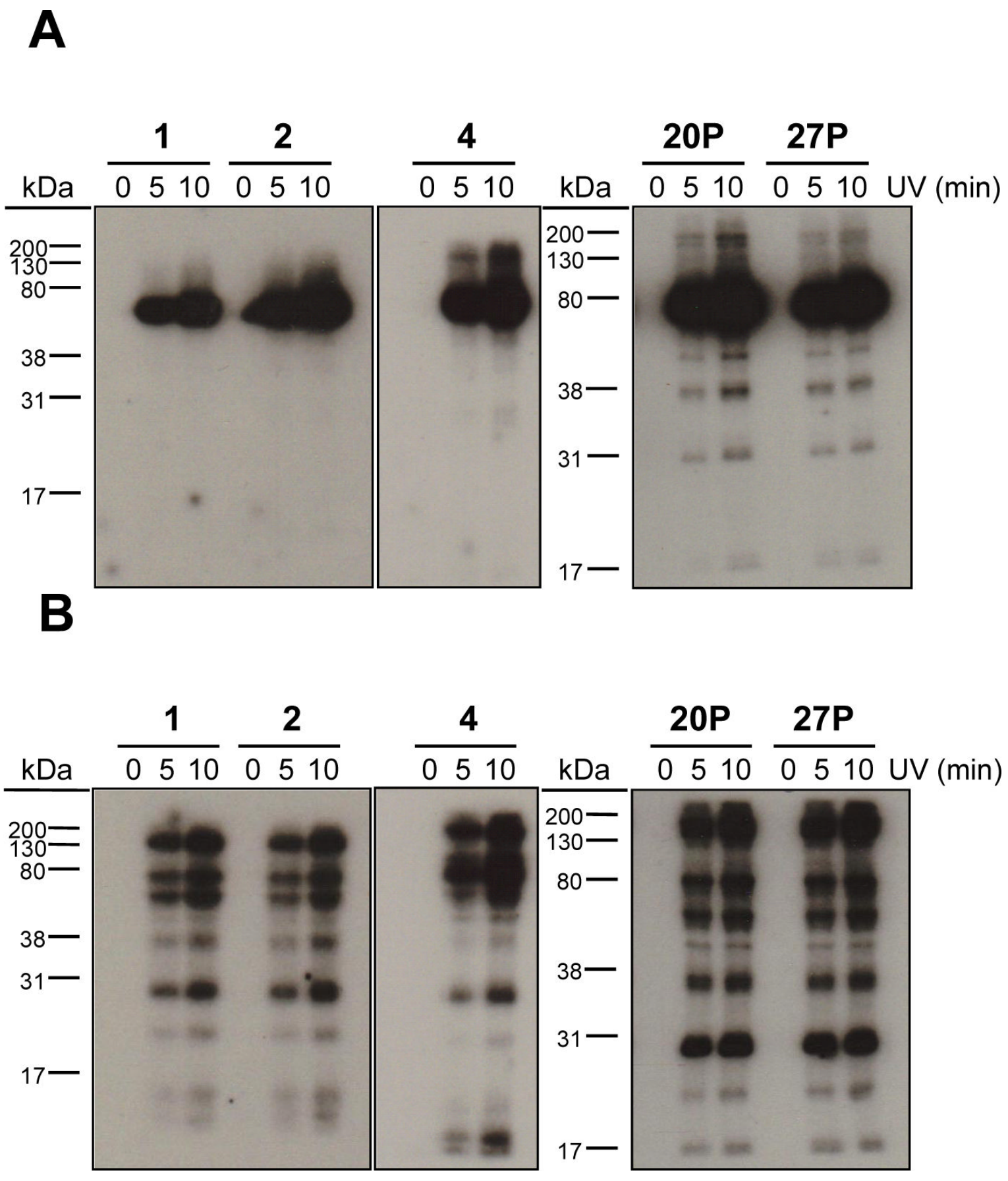

Figure 1.

Covalent modification of plasma proteins by benzophenone-containing LPA analogues.

Plasma (5\% in PBS) from Sprague-Dawley (19.4 mg albumin/mL) A or Nagase rats $(0.4 \mathrm{mg}$ albumin/mL) B was incubated with compounds 1, 2, 4, 20P, or 27P $(50 \mathrm{nM}$, DMSO $10 \%$ final concentration) in the dark for $30 \mathrm{~min}$ prior to UV irradiation for up to $10 \mathrm{~min}$ on ice. Samples were diluted with $2 \times$ sample loading buffer and separated by SDS-PAGE. Gels were subsequently dried and radioactive bands were visualized by autoradiography. 